\title{
FEMOCION DE CAVIDAD ABDOMINAL DE UN DISPOSITIVO INTRAUTERINO POR CULDOSCOPIA
}

\author{
Dr. EDUARDO ACOSTA BENDEK*
}

Una de las complicaciones más serias de los dispositivos intrauterinos es la perforación uterina, la cual se inicia desde el momento de su inserción. La frecuencia de esta complicación varía de acuerdo al tipo de dispositivo usado; así tenemos que con el asa de Lippes es de 1: 2.500. con la del Dalkon Shield es de 1: 350 (2), y la $\mathrm{T}$ o 7 de cobre es de 1: 5000 (3). Esta complicación se puede reducir al máximo si guardamos ciertos principios en su aplicación como son: el examen ginecológico, el uso de sonda uterina y la aplicación de una pinza de cuello uterino previo a la inserción (1). El objeto de la publicación del presente caso es resaltar la importancia de la endoscopia ginecológica en la resolución de este tipo de complicación con un mínimo de riesgo y costo.

\section{HISTORIA CLINICA:}

Paciente de 21 años, casada, grávida I, para I, cesárea por desproporción cefalo-pélvica en Oct./74; postoperatorio complicado con infección pélvica que cedió al tratamiento médico a los 15 días. La paciente presentó amenorrea hasta los 7 meses después de operada. En Junio/75, bajo anestesia raquídea le aplicaron un Lippes D. Un mes más tarde registró un dolor tipo cólico de localización

pélvica que se siguió repitiendo mensualmente hasta el mes de Nov./75, cólico que cedía al tratamiento médico.

Consultó en Diciembre del mismo año por amenorrea, cólicos y chequeo del dispositivo. Al examen pélvico se encontró útero y anexos normales; no se visuaīizó el hilo del D.I.U. Se exploró útero con histerómetro y cucharilla de Novak, no se detectó presencia de D.I.U. dentro del útero. Se trató de hacer un histerograma el cual hubo de suspenderse por dolor en hipocondrio izq; la placa radiográfica en ese momento mostró introducción del medio de contraste en los vasos útero-ovaricos. Figura No 1.

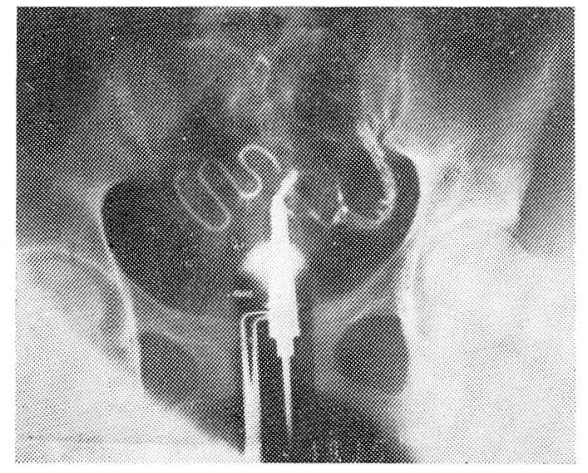

Histerosal Pingografía Infiltración del medio de contraste "Decano de Ciencias de la Salud de la U. Metro-
politana Barranquilla, Colombia. 
Se procedió a introducir un histerómetro en cavidad uterina y tomar una radiografía simple en A.P. y L. Figuras Nos. 2 y 3.

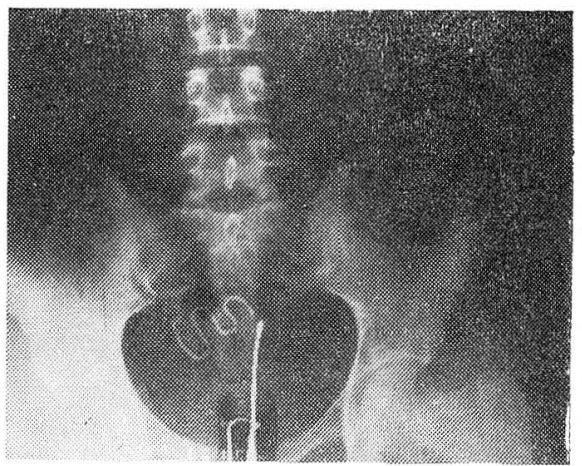

Radiografía simp̨le en A. P. con sonda Uterina.

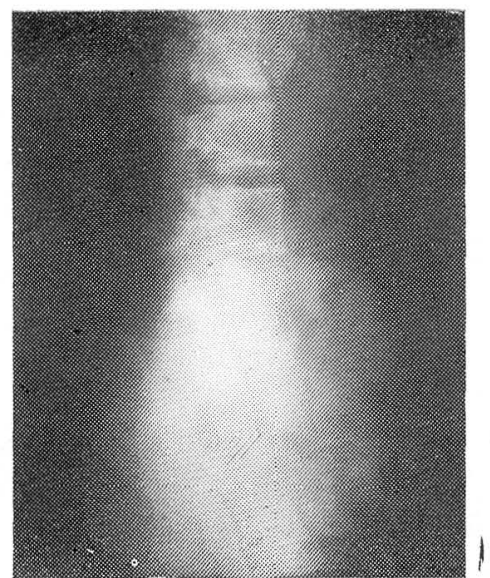

Radiografía simple en posición lateral con sonda uterina.

Se localizó el dispositivo en cavidad abdominal. Se procedió a hospitalizar la paciente para hacer la extracción del D.I.U. por Culdoscopía. Durante el procedimiento se observó que el D.I.U. había perforado la pared posterior del útero en su borde lateral derecho, cerca del cuerno uterino, quedando la parte terminal del espi- ral aún introducido en el miometrio; el resto del espiral se encontraba adherido a la hoja posterior del ligamento ancho. Figuras Nos. 4 y 5.

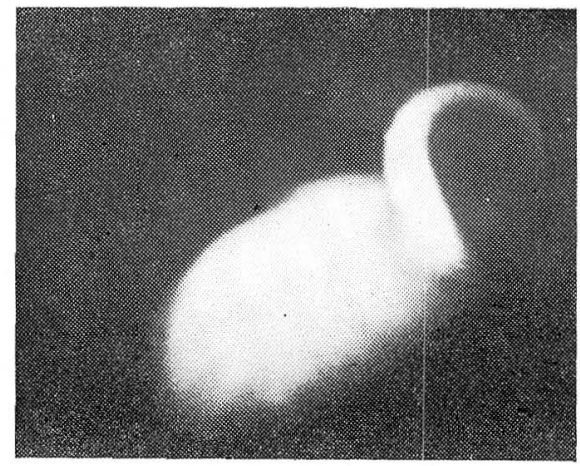

Extremo terminal del D. I. U.; saliendo del útero

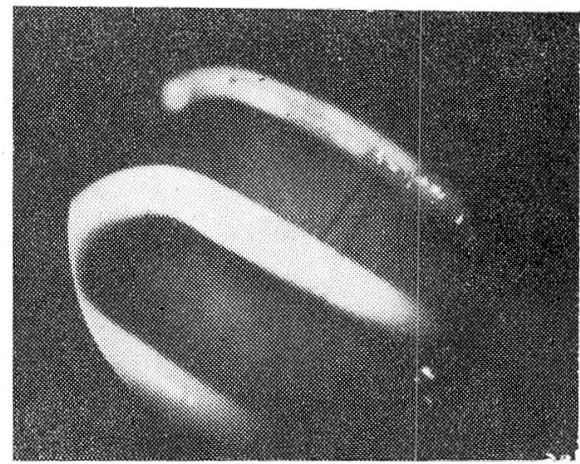

Parte del espiral, fuera de la cavidad Uterina.

Con la ayuda del Culdoscopio se introdujo la pinza de Gutiérrez Nadjar en cavidad abdominal, pudiéndose extraer el D.I.U. sin ninguna dificultad. El postoperatorio fue normal. La amenorrea se trató a base de tratamiento hormonal cíclico de seis meses. Consiguiéndose un sangrado menstrual; actualmente sus ciclos son regulares y espontáneos. Ver Figuras Nos. 6 y 7. 


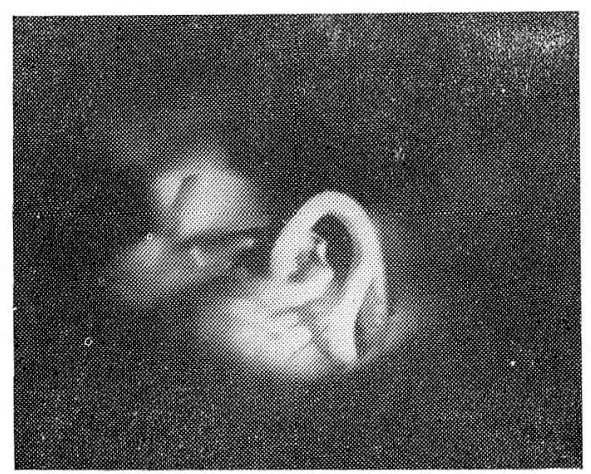

Dispositivo en cavidad vaginal.

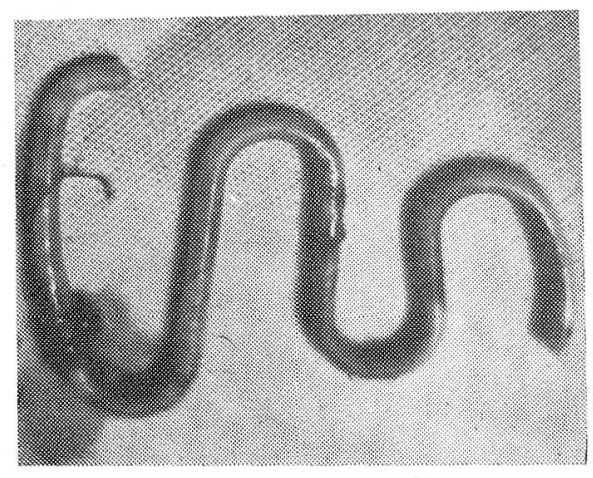

Disposiùivo extraído.

\section{COMENTARIOS:}

Entre las complicaciones más serias de los dispositivos intrauterinos se encuentra la perforación del útero, la cual se inicia en el momento de su inserción o también por la presión que el extremo interno del dispositivo ejerce sobre el útero durante la contracción lo cual produce necrosis seguida de una progresiva inmigración a través de la pared uterina. Estas complicaciones pueden ser evitatadas si se conservan ciertos requisitos aconsejados en su aplicación. Antes de proceder a cualquier tratamiento quirúrgico debe el médico estar seguro del diagnóstico ya que la ausencia del hilo del D.I.U. en vagina o cérvix no es dato suficiente para hacer el diagnóstico de éste en cavidad abdominal. Como son varias las posibilidades que se pueden presentar, hay que recurrir a un método de diagnóstico preciso como es el uso de los Rayos X, bien haciendo una radiografía del útero con medio de contraste o colocando una sonda uterina en su interior y tomando una placa en sentido A.P. y L. que nos da el diagnóstico exacto del lugar donde se encuenta el D. I. U. (4). Una vez com. probado el diagnóstico soy de opinión que la conducta más saludable debe ser la remoción del dispositivo, sea de cualquier tipo, que haya causado dicha complicación, ya que además de las posibles complicaciones o molestias que puede producir en la paciente, se asocia el trauma sicológico de ésta al estar consciente de tener dentro de su abdomen un cuerpo extraño; y más se justifica esta conducta cuando hoy contamos con procedimientos endoscópicos, coco la Culdoscopía o Laparoscopía que permiten su remoción con muy escaso riesgo. La aplicación del D.I.U. bajo anestesia raquídea fue un factor decisivo en la causa de esta complicación.

La amenorrea presentada por la paciente fue de causa uterina producida por el proceso séptico, que ocasionó la destrucción parcial del endometrio como se demostró por la biopsia tomada durante el procedimiento culdoscópico y que se recuperó después de un tratamiento hormonal cíclico de seis meses.

\section{BIBLIOGRAFIA:}

1. - MISHELL JR. D.R.: Estado actual de los esteroides anticonceptivos y de los dispositi- 
vos intrauterinos. Clínicas Obstétricas y Ginecológicas. Pág. 35, Marzo 1974.

2. - SNOWDEN R ., WILLIAMS M.: 'The use effectivenes, 3 of the Dalkon Shield in the Kingdom. Contraception. 7:91, 1973.

3. - TATUM H. J.: Dispositivos in-
Rev. Col. Obst. y Ginec.

trauterinos portadores de cobre. Clínicas Obstétricas y Ginecológicas. Pág. 91, marzo 1974.

4. - TIMONEN H. Y COLS. Hystero. graphic studies uith the copper $\mathrm{T}$ in situ. Contraception 6: 513 , 1972 . 